\title{
Should We Measure Adenoma Detection Rate for Gastroenterology Fellows in Training?
}

\author{
Mustapha M. El-Halabi ${ }^{a}$, Patrick R. Barrett ${ }^{\mathrm{a}}$, Melissa Martinez Mateo ${ }^{\mathrm{a}}$, \\ Nabil F. Fayad, b, c
}

\begin{abstract}
Background: Adenoma detection rate (ADR) is a proven quality metric for colonoscopy. The value of ADR for the evaluation of gastroenterology fellows is not well established. The aim of this study is to calculate and evaluate the utility of ADR as a measure of competency for gastroenterology fellows.
\end{abstract}

Methods: Colonoscopies for the purposes of screening and surveillance, on which gastroenterology fellows participated at the Richard L. Roudebush VAMC (one of the primary training sites at Indiana University), during a 9-month period, were included. $\mathrm{ADR}$, cecal intubation rate, and indirect withdrawal time were measured. These metrics were compared between the levels of training.

Results: A total of 591 screening and surveillance colonoscopies were performed by 14 fellows. This included six, four and four fellows, in the first, second and third year of clinical training, respectively. Fellows were on rotation at the VAMC for a mean of 1.9 months (range 1 to 3 months) during the study period. The average ADR was $68.8 \%(95 \%$ CI $65.37-72.24)$. The average withdrawal time was $27.59 \mathrm{~min}(95 \%$ CI 23.45 - 31.73). The average cecal intubation rate was 99\% (95\% CI 98-100\%). There was no significant difference between ADRs, cecal intubation rates, and withdrawal times at different levels of training; however, a trend toward swifter withdrawal times with advancing training was noted.

Conclusions: ADR appears not to be a useful measure of competency for gastroenterology fellows. Consideration should be given to alternative metrics that could avoid bias and confounders.

Keywords: Adenoma detection rate; Colonoscopy training; Gastroenterology fellowship; Colonoscopy competency assessment

Manuscript submitted May 9, 2018, accepted May 29, 2018

a Division of Gastroenterology and Hepatology, Indiana University School of Medicine, Indianapolis, IN, USA

${ }^{\mathrm{b}}$ Section of Gastroenterology and Hepatology, Richard L. Roudebush VA Medical Center, Indianapolis, IN, USA

${ }^{c}$ Corresponding Author: Nabil F. Fayad, 702 Rotary Circle, Suite 225, Indianapolis, IN 46202, USA. Email: nfayad@iu.edu

doi: https://doi.org/10.14740/gr1043w

\section{Introduction}

Colorectal cancer (CRC) is the third most common cancer in the United States $[1,2]$. Colonoscopy has been proven to decrease CRC mortality [3-5]. However, a careful examination of the entire colonic mucosa is essential to reduce CRC incidence. Few quality indicators have been proposed in the recent years as surrogate measures for careful mucosal examination. The most robust quality indicator is the adenoma detection rate (ADR), or the proportion of screening colonoscopies where at least one adenoma is detected. It has been shown that ADR and incidence of interval colon cancer after a screening colonoscopy are inversely proportional $[4,6]$. Therefore, the American Society of Gastrointestinal Endoscopy (ASGE)/American College of Gastroenterology (ACG) Task Force on Quality in Endoscopy increased in 2015 the minimum ADR benchmarks for both sexes to $25 \%$, from $20 \%$ (30\% for males, $20 \%$ for females) [3]. Subsequently, there has been an increased interest in determining the factors that affect the adenoma detection, and the most important factor has been shown to be the endoscopist themselves [7]. Appropriate training in colonoscopy is therefore fundamental in increasing ADR and decreasing interval colon cancer incidence.

Endoscopy competence during GI fellowship is typically evaluated by the trainers' subjective assessment of overall competence and by meeting an arbitrary volume threshold for procedures completed [8]. A decade ago, the volume of colonoscopies to be completed by the end of fellowship training was set to be 140 by the GI societies [9]. This number has been questioned since, and some studies suggest that 500 colonoscopies are required to achieve proficiency $[10,11]$. The Accreditation Council for Graduate Medical Education (ACGME) now emphasizes the importance of medical trainees meeting specific performance benchmarks and demonstrating readiness for unsupervised practice. They define this approach as Competency-Based Medical Education (CBME), but they do not provide any specific metrics that need to be measured to assess competency in colonoscopy. A recent survey including most GI training programs in the United States revealed that less than one third of programs use any skills assessment tool or specific quality metrics in determining their trainees' competency in colonoscopy [12]. In 2014, the ASGE released an evaluation tool for assessment of competency in endoscopy (ACE) that included assessment of six motor and six cognitive 
Table 1. Average ADR and Withdrawal Time per Year of Training

\begin{tabular}{llll}
\hline Level of training & Total procedures & Withdrawal time (minutes:seconds) (95\% CI) & ADR \\
\hline First year & 330 & $28: 19(24: 19-32: 10)$ & $67.68 \%$ \\
Second year & 179 & $27: 19(20: 19-33: 59)$ & $74.05 \%$ \\
Third year & 257 & $24: 05(16: 35-31: 36)$ & $73.73 \%$ \\
\hline
\end{tabular}

skills; this does not include any known colonoscopy quality metrics [13].

As mentioned earlier, ADR is the most robust colonoscopy quality metric for practicing gastroenterologists, but the value of ADR as a competency measurement for the evaluation of gastroenterology fellows during their different stages of training is not well established. Limited literature has been published on this topic, with inconsistent results [14-21]. The aim of this study was to calculate ADR and evaluate its utility as a measure of competency for gastroenterology fellows.

\section{Methods}

This study was a quality improvement project performed by all gastroenterology fellows at Indiana University in the academic year 2014 - 2015.

First, all colonoscopies in which gastroenterology fellows participated at the Richard L. Roudebush VAMC (one of the primary training sites at Indiana University), during a 9-month period, were identified using our electronic endoscopy software (Provation, Wolters Kluwer, Netherlands). All colonoscopies that did not have a fellow involved were excluded. We included colonoscopies that were performed for average risk and high risk screening for colon cancer, as well as colonoscopies that were performed for polyp surveillance. All colonoscopies performed for other indications were excluded from the analysis, including referrals for polyp removal. Patients who had a surgical resection of a segment of their colon were also excluded, as were procedures aborted before reaching the cecum due to inadequate bowel preparation quality.

All 14 fellows in the program rotated at the VAMC during the study period for a variable number of months. All procedures were performed with high-definition colonoscopes (Olympus America Inc., Center Valley, Pennsylvania, USA) under white light, with direct attending supervision. Fellows always started the procedure and proceeded to completion unless they were unable to despite guidance from their attending. The level of attending's involvement in each case was variable and was not accounted for in this study due to lack of this information on procedure reports.

Using the procedure report of each included colonoscopy, we collected only three data points: presence or absence of at least one adenoma, cecal intubation, and indirect withdrawal time (the time elapsed from the beginning of inspecting the cecum to the complete withdrawal of the colonoscope, inclusive of polypectomy maneuvers). ADR for each fellow was then calculated by dividing the number of colonoscopies with at least one adenoma by the total number of included colonos- copies performed by the same fellow. Hyperplastic and sessile serrated polyps were excluded from the analysis. These metrics (ADR, cecal intubation rate, and average withdrawal time) were then compared between the levels of training using $t$-tests and ANOVA.

This study was a quality improvement project and did not require IRB approval.

\section{Results}

The study started in September 2014, and was conducted over 9 months. A total of 591 colonoscopies were performed by 14 fellows during that period. This included six fellows in the first year of clinical training, four fellows in the second year and four fellows in the third year of training. Fellows were on rotation at the VAMC for a mean of 1.9 months (range 1 to 3 months) during the study period. Out of 591 colonoscopies, 386 had at least one adenoma. The average ADR for the entire study population was $68.8 \%$ (95\% CI 65.4 - 72.2). The overall average withdrawal time for fellows was 26:30 (minutes:seconds) (95\% CI 24:28 - 29:14). The average cecal intubation rate was $99 \%$ (95\% CI 98-100\%).

Tables 1 and 2 summarize our data. There was no significant difference between ADRs $(P=0.27)$, cecal intubation rates $(\mathrm{P}=\mathrm{NS})$, and withdrawal times $(\mathrm{P}=\mathrm{NS})$ at different levels of training. There was no significant difference in ADR when comparing lower level fellows vs. upper level fellows (P $=0.09)$, or first year fellows vs. third year fellows $(\mathrm{P}=0.07)$ or second year fellows vs. third year fellows $(\mathrm{P}=0.95)$.

However, a trend toward swifter withdrawal times with advancing training was noted with a P-value of 0.09 when comparing withdrawal times between first year fellows and third year fellows.

\section{Discussion}

The aim of our study was to compare ADRs between different levels of training to assess whether ADR, a proven colonoscopy quality indicator, can be used to determine competency in colonoscopy during fellowship training. We did not find any difference in ADR across levels of training. Therefore, ADR cannot provide a useful assessment of competency for gastroenterology fellows, and should not be measured for trainees. In fact, direct supervision by an attending can be expected to correct fellows' deficiencies in detecting adenomas. Further, Peters et al noted that involvement of fellows in screening colonoscopies increases the ADR, as two pairs of eyes are better than one, particularly if the second set of eyes is also expe- 
Table 2. Colonoscopy Quality Metrics per Fellow

\begin{tabular}{|lllllll}
\hline Level of training & Fellow & Total procedures & $\begin{array}{l}\text { Procedures with } \\
\text { adenomas detected }\end{array}$ & Cecal intubation rate & $\begin{array}{l}\text { Average withdrawal } \\
\text { time (minutes:seconds) }\end{array}$ & $\begin{array}{l}\text { Adenoma } \\
\text { detection rate }\end{array}$ \\
\hline 1 & 1 & 47 & 29 & $100 \%$ & $29: 28$ & $61.70 \%$ \\
\hline 1 & 2 & 61 & 42 & $100 \%$ & $32: 27$ & $68.85 \%$ \\
\hline 1 & 3 & 37 & 27 & $100 \%$ & $22: 09$ & $72.97 \%$ \\
\hline 1 & 4 & 46 & 35 & $100 \%$ & $30: 13$ & $76.09 \%$ \\
\hline 1 & 5 & 27 & 18 & $93 \%$ & $28: 15$ & $66.67 \%$ \\
\hline 1 & 6 & 112 & 67 & $99 \%$ & $24: 27$ & $59.82 \%$ \\
\hline 2 & 7 & 61 & 39 & $98 \%$ & $31: 39$ & $63.93 \%$ \\
\hline 2 & 8 & 37 & 27 & $100 \%$ & $29: 30$ & $72.97 \%$ \\
\hline 2 & 9 & 53 & 39 & $100 \%$ & $24: 30$ & $73.58 \%$ \\
\hline 3 & 10 & 28 & 24 & $100 \%$ & $23: 12$ & $85.71 \%$ \\
\hline 3 & 11 & 66 & 47 & $99 \%$ & $26: 03$ & $71.21 \%$ \\
\hline
\end{tabular}

rienced [15]. In addition, the reliability of ADR is proven when calculated with over 500 average-risk screening colonoscopies [22] which are challenging to apply for trainees during their fellowship timespan.

As we previously stated, there is a very limited number of studies investigating the ADR of fellows. Most of these studies focused on comparing the ADR of the gastroenterology attending with and without fellow involvement in the procedure $[15,17-21]$. Two of these studies $[15,19]$ reported higher ADR when fellows were involved, while one meta-analysis did not show an effect on ADR when fellows were involved [17]. Unlike our study, two studies found significant difference in ADR of fellows at the early stages of training, compared to fellows at later stages of their training [14, 15]. Gianotti et al [14] showed that fellows' ADR increased after performing more than 140 colonoscopies and Peters et al [15] showed that ADR increased significantly with each year of training. Both studies $[14,15]$ were done in the United States, where trainees should have direct supervision with the staff endoscopist present in the same procedure room. In our study, there was a difference between ADR of first and third year fellows, which did not reach significance $(67.7 \%$ vs. $73.7 \%$; $=0.07)$. In contrast, the study of Van Doorn et al [16] was the only study that reported actual independent fellow ADR, as it was done in the Netherlands where fellows are allowed to perform colonoscopies without direct supervision (supervising faculty not present during the withdrawal process after the fellow has performed 100 supervised colonoscopies). However, this study is not comparable to ours because it did not attempt to compare the ADR of fellows during different levels of training, and rather compared ADR during training to ADR during the first years of unsupervised practice.

Prospective determination of maximal insertion independently reached by fellows can provide a good assessment of scope manipulation by the fellows. However, it does not ap- pear possible to rely on ADR to assess fellows' skills in mucosal inspection and lesion detection, as one might conclude from the studies by Peters et al [15] and Van Doorn et al [16]. An alternative option would be to have the fellow complete an independent examination of the colonic mucosa during withdrawal, followed by a repeat examination by the attending to check for missed lesions. However, this is not practical in most cases, and further, it is subject to the established effect of increased detection with tandem colonoscopies [23].

Our study included a fairly large number of fellows, with balanced distribution between years of training, and was conducted over a 9-month period. We also had a fairly balanced number of procedures per fellow within each year of training, with the total number of colonoscopies performed by all the fellows in the same year of training distributed almost equally between them. We had at least four fellows participating per year of training. The limitations of the study are the inclusion of a single training site, as well as the variability in attending involvement during procedures, which makes it difficult to objectively estimate fellows' ADR. Attending supervision and guidance is definitely a very important factor when studying fellows' performance as discussed above, but since we were not able to quantify or even assess the attending involvement in these colonoscopies, we had to eliminate this factor from our analysis. The number of colonoscopies performed by each fellow was also relatively small, ranging between 40 and 100 for most participants. Another possible limitation of our study was the inclusion of surveillance colonoscopies to increase the included colonoscopy numbers, since this was a quality improvement project by the fellows designed to be completed over a one academic year span. Inclusion of surveillance colonoscopies might have contributed to elevated ADRs seen across the board, and might have masked potential differences between true ADRs. This increased mean ADR is also reported in other studies on veterans, with an average measured ADR 
when including screening and surveillance colonoscopies of $68.9 \%$ [24], almost identical to our own average measured ADR of $68.8 \%$.

\section{Conclusions}

ADR is not useful to assess fellows' competency in colonoscopy training. Alternative quality metrics that could avoid bias and confounders are not currently available. We continue to rely primarily on evaluations by attending physicians, and efforts should be enhanced to educate them in using available formative and summative colonoscopy assessment tools, and providing adequate feedback to trainees.

\section{Declarations}

The authors have no conflict of interest to declare.

\section{Financial Support}

None.

\section{References}

1. Edwards BK, Ward E, Kohler BA, Eheman C, Zauber AG, Anderson RN, Jemal A, et al. Annual report to the nation on the status of cancer, 1975-2006, featuring colorectal cancer trends and impact of interventions (risk factors, screening, and treatment) to reduce future rates. Cancer. 2010;116(3):544-573.

2. Siegel R, Naishadham D, Jemal A. Cancer statistics, 2013. CA Cancer J Clin. 2013;63(1):11-30.

3. Rex DK, Schoenfeld PS, Cohen J, Pike IM, Adler DG, Fennerty MB, Lieb JG, 2nd, et al. Quality indicators for colonoscopy. Gastrointest Endosc. 2015;81(1):31-53.

4. Corley DA, Jensen CD, Marks AR, Zhao WK, Lee JK, Doubeni CA, Zauber AG, et al. Adenoma detection rate and risk of colorectal cancer and death. N Engl J Med. 2014;370(14):1298-1306.

5. Kahi CJ, Imperiale TF, Juliar BE, Rex DK. Effect of screening colonoscopy on colorectal cancer incidence and mortality. Clin Gastroenterol Hepatol. 2009;7(7):770775; quiz 711.

6. Kaminski MF, Regula J, Kraszewska E, Polkowski M, Wojciechowska U, Didkowska J, Zwierko M, et al. Quality indicators for colonoscopy and the risk of interval cancer. N Engl J Med. 2010;362(19):1795-1803.

7. Chen SC, Rex DK. Endoscopist can be more powerful than age and male gender in predicting adenoma detection at colonoscopy. Am J Gastroenterol. 2007;102(4):856861.

8. Training Committee, Sedlack RE, Shami VM, Adler DG, Coyle WJ, DeGregorio B, Dua KS, et al. Colonoscopy core curriculum. Gastrointest Endosc. 2012;76(3):482-
490.

9. American Association for the Study of Liver Diseases, American College of Gastroenterology, American Gastroenterological Association Institute, American Society for Gastrointestinal Endoscopy. The Gastroenterology Core Curriculum, Third Edition. Gastroenterology. 2007;132(5):2012-2018.

10. Spier BJ, Benson M, Pfau PR, Nelligan G, Lucey MR, Gaumnitz EA. Colonoscopy training in gastroenterology fellowships: determining competence. Gastrointest Endosc. 2010;71(2):319-324.

11. Patwardhan VR, Feuerstein JD, Sengupta N, Lewandowski JJ, Tsao R, Kothari D, Anastopoulos HT, et al. Fellowship colonoscopy training and preparedness for independent gastroenterology practice. J Clin Gastroenterol. 2016;50(1):45-51.

12. Patel SG, Keswani R, Elta G, Saini S, Menard-Katcher P, Del Valle J, Hosford L, et al. Status of competencybased medical education in endoscopy training: a nationwide survey of US ACGME-Accredited gastroenterology training programs. Am J Gastroenterol. 2015;110(7):956962.

13. Committee AT, Sedlack RE, Coyle WJ, Obstein KL, Al-Haddad MA, Bakis G, Christie JA, et al. ASGE's assessment of competency in endoscopy evaluation tools for colonoscopy and EGD. Gastrointest Endosc. 2014;79(1):1-7.

14. Gianotti RJ, Oza SS, Tapper EB, Kothari D, Sheth SG. A longitudinal study of adenoma detection rate in gastroenterology fellowship training. Dig Dis Sci. 2016;61(10):2831-2837.

15. Peters SL, Hasan AG, Jacobson NB, Austin GL. Level of fellowship training increases adenoma detection rates. Clin Gastroenterol Hepatol. 2010;8(5):439-442.

16. van Doorn SC, Klanderman RB, Hazewinkel Y, Fockens P, Dekker E. Adenoma detection rate varies greatly during colonoscopy training. Gastrointest Endosc. 2015;82(1):122-129.

17. Oh YS, Collins CL, Virani S, Kim MS, Slicker JA, Jackson JL. Lack of impact on polyp detection by fellow involvement during colonoscopy: a meta-analysis. Dig Dis Sci. 2013;58(12):3413-3421.

18. Buchner AM, Shahid MW, Heckman MG, Diehl NN, McNeil RB, Cleveland P, Gill KR, et al. Trainee participation is associated with increased small adenoma detection. Gastrointest Endosc. 2011;73(6):1223-1231.

19. Rogart JN, Siddiqui UD, Jamidar PA, Aslanian HR. Fellow involvement may increase adenoma detection rates during colonoscopy. Am J Gastroenterol. 2008;103(11):2841-2846.

20. Eckardt AJ, Swales C, Bhattacharya K, Wassef WY, Leung K, Levey JM. Does trainee participation during colonoscopy affect adenoma detection rates? Dis Colon Rectum. 2009;52(7):1337-1344.

21. Chalifoux SL, Rao DS, Wani SB, Sharma P, Bansal A, Gupta N, Rastogi A. Trainee participation and adenoma detection rates during screening colonoscopies. J Clin Gastroenterol. 2014;48(6):524-529.

22. Do A, Weinberg J, Kakkar A, Jacobson BC. Reliability of 
adenoma detection rate is based on procedural volume. Gastrointest Endosc. 2013;77(3):376-380.

23. Rex DK, Cutler CS, Lemmel GT, Rahmani EY, Clark DW, Helper DJ, Lehman GA, et al. Colonoscopic miss rates of adenomas determined by back-to-back colonos- copies. Gastroenterology. 1997;112(1):24-28.

24. Clark BT, Protiva P, Nagar A, Imaeda A, Ciarleglio MM, Deng Y, Laine L. Quantification of adequate bowel preparation for screening or surveillance colonoscopy in men. Gastroenterology. 2016;150(2):396-405; quiz e314-395. 